\title{
Enhanced pro-coagulant hemostatic agents based on nanometric zeolites
}

\author{
Juliana Bergamasco Laurenti a , Gabriel Zazeri a , Ana Paula Ribeiro Povinelli a \\ Moacir Fernandes de Godoy ${ }^{\mathrm{b}}$, Domingo Marcolino Braile ${ }^{\mathrm{c}}$, Tânia R. Flores da Rocha ${ }^{\mathrm{d}}$, \\ Élbio Antônio D' Amico ${ }^{\mathrm{d}}$, José Geraldo Nery ${ }^{\mathrm{a}, *}$ \\ a Department of Physics, Institute of Biosciences, Letters and Exact Sciences, UNESP-São Paulo State University, Campus de Sao José do Rio Preto, São Paulo \\ 15054-000, Brazil \\ ${ }^{\mathrm{b}}$ Department of Cardiology and Cardiovascular Surgery, School of Medicine of São José do Rio Preto, São Paulo 15054-000, Brazil

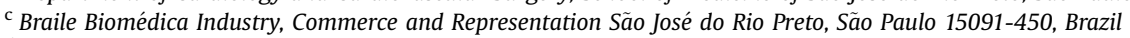 \\ ${ }^{\mathrm{d}}$ Laboratory of Hemostasis, Hospital of the Faculty of Medicine, University of São Paulo, USP-SP, São Paulo 05403-000, Brazil
}

\section{A R T I C L E I N F O}

\section{Article history:}

Received 16 August 2016

Received in revised form 14 October 2016

Accepted 16 October 2016

Available online 17 October 2016

\section{Keywords:}

Hemorrhage

Nanometric zeolites

Inorganic

Hemostatic agents

\begin{abstract}
A B S T R A C T
Micro-and nanometric faujasite zeolites were tested as hemostatic coagulant agents. The as-made zeolites and their calcium ion exchanged derivatives were characterized by XRD, SEM, AFM, TGA, and DSC. Zeta potential measurements of the micro and nanometric zeolites, as a function of $\mathrm{pH}(1-12.5)$, revealed the hemostatic potential of the materials. The isoelectric point for FAU, FAU/Ca, Nano-FAU, and NanoFAU/Ca were measured at $\mathrm{pH} 2.0,1.9,3.2$, and 2.5, respectively. The hemostatic activity was confirmed by the TEG technique for both micro and nanometric zeolites, however a superior activity were observed for the nanometric materials. FAU and FAU/Ca exhibited a reduction of the R parameter (defined as period of time of latency from the start of test to initial fibrin formation for the formation of a clot of an amplitude of $2 \mathrm{~mm}$ ) from $8.6 \pm 0.7 \mathrm{~min}$ (control) to $3.2 \pm 0.7 \mathrm{~min}$ and $2.3 \pm 0.1 \mathrm{~min}$, respectively. On the other hand, for the Nano-FAU, and Nano-FAU/Ca the observed decrease were to $2.4 \pm 0.6 \mathrm{~min}$, and $1.1 \pm 0.2 \mathrm{~min}$, respectively. The amounts of heat released were $105.60 \mathrm{~J} / \mathrm{g}$ (FAU), $65.8 \mathrm{~J} / \mathrm{g}$ (FAU/Ca), $85.48 \mathrm{~J} /$ $\mathrm{g}$ (Nano-FAU), and $78.21 \mathrm{~J} / \mathrm{g}$ (Nano-FAU/Ca). Statistical analysis using one-way analysis of variance showed a global value of $\mathrm{p}<0.0001$. Tukey-Kramer multiple comparisons revealed significant ( $\mathrm{p}<0.0001$ ) differences for FAU, FAU/Ca, Nano-FAU, and Nano-FAU/Ca, relative to the control. Nano-FAU/ Ca showed the most important reductions of the $\mathrm{R}$ with significant differences compared to the control ( $\mathrm{p}<0.0001$ and $\mathrm{p}<0.0001$, respectively) and FAU ( $\mathrm{p}=0.0071$ for the $\mathrm{R}$ parameter).
\end{abstract}

(C) 2016 Elsevier Inc. All rights reserved.

\section{Introduction}

Hemostatic coagulant agents are materials capable of reducing bleeding and can be grouped into three classes, depending on their mechanism of action: factor concentrators [1], mucoadhesive agents [2], and procoagulants [3,4]. They can also be grouped according to their forms and types: solid sheets, normally known as hemostatic dressings [5]; solid particles, or powders and fibers [3]; hydrogels [6]; liquid tissue sealants [7]; dispersions made from natural [8] or synthetic polymers [9], ceramics [10] clays such as smectite and kaolin [11-13]. Several of these materials have been

\footnotetext{
* Corresponding author.

E-mail address: nery@ibilce.unesp.br (J.G. Nery).
}

reported to be used as hemostatic agents both in their pure forms or combined with other materials $[10,14]$. Among the inorganic classes of materials, zeolites have attracted the attention of the scientific and medical communities for their potential use as efficient hemostatic agents.

Hemostatic agent employing dehydrated zeolites as powder dressing was employed during the Iraq war 2003 under the trademark QuikClot ${ }^{\circledR}$ (Z-Medica, Wallingford, CT) [3,15-17]. In principle it acts as a molecular sieve, adsorbing water molecules at the wound site and increasing the concentrations of clotting factors, platelets, and erythrocytes in order to stimulate hemostasis $[18,19]$. Other authors have studied different classes of composites based on zeolites with the purpose of finding more efficient hemostatic agents. Zhang et al. [9] developed an antibiotics-loaded zeolite/polymer composite for hemostatic applications, while 
Mortazavi et al. [20] showed that a mixture of bentonite and zeolite minerals could dramatically reduce bleeding and the volume of blood loss, as well as the clotting time, and observed a control of exothermic reactions, which eliminated the risk of burning in the wound. Alavi et al. [21] studied in vivo the effects of a new impregnated sterile gauze containing bentonite and halloysite minerals on blood coagulation and the wound healing rate in male Wistar rats, and it was observed that topical application of this material decreased the clotting time and accelerated the wound healing rate.

Despite the beneficial effects of zeolites in accelerating blood coagulation and shortening the clot formation time, the main drawback of their use is related to the exothermic reaction, which can reach temperatures higher than $100{ }^{\circ} \mathrm{C}\left(212^{\circ} \mathrm{F}\right)$ and cause fullthickness tissue damage $[22,23]$. Several methods have been tested to attenuate this adverse effect, such as ion exchange treatment of the as-made zeolites using $\mathrm{K}^{+}, \mathrm{Ba}^{2+}, \mathrm{Sr}^{2+}$, or $\mathrm{Ag}^{+}$. A heat reduction from $680 \mathrm{~J} / \mathrm{g}$ to $420 \mathrm{~J} / \mathrm{g}$ was reported for ion exchange in Linde Type 5A zeolite using $\mathrm{Ag}^{+}$ions [24].

Reduction of particle size from the micrometric to the nanometric scale leads to substantial changes in the properties of the materials, which in turn affects the performance of zeolites in the traditional applications areas such as catalysis and separation [25]. A survey of the literature will show that the hemostatic agents based on zeolitic materials that have so far been tested appear to be on the micrometric scale. To the best of our knowledge no study concerning the behavior of nanometric zeolites used as hemostatic coagulation agents has until now been reported. Therefore, the questions raised in this study are: a) Does zeolite size (micrometric or nanometric) affect the coagulation cascade? b) Does it affect the collateral damage of burning? With the aim of answering these questions, systematic studies were undertaken with micrometric and nanometric faujasite zeolites hydrothermally synthesized, ion exchanged with calcium, characterized by several spectroscopic techniques, and tested as hemostatic agents using in vitro thromboelastography assays to observe the acceleration in clotting time.

\section{Experimental section}

\subsection{Chemicals}

The preparation of the faujasite zeolite and the ion exchange experiments employed the following chemicals: sodium hydroxide pellets ( $\mathrm{NaOH}, 98 \%$, Sigma-Aldrich, Steinheim, Germany), sodium aluminate $\left(\mathrm{NaAlO}_{2}\right.$, Sigma-Aldrich, Steinheim, Germany), fumed silica $\left(\mathrm{SiO}_{2}, 99.8 \%\right.$, Sigma-Aldrich, Steinheim, Germany), and calcium chloride dihydrate $\left(\mathrm{CaCl}_{2} \cdot 2 \mathrm{H}_{2} \mathrm{O}\right.$, Merck, Darmstadt, Germany). All the chemicals were used as received. In vitro assays were performed with human blood samples. All the patients who participated in this study gave informed consent before blood donation. The study was approved by the Research Ethics Committee of FAMERP (São José do Rio Preto Medical School) under the protocol number CAAE 48358215.9.0000.5415.

\subsection{Preparation of materials}

\subsubsection{Synthesis of as-made micrometric and nanometric faujasite zeolites}

The nanometric faujasite zeolite was synthesized by hydrothermal crystallization, following the procedure reported by Zhan et al. [26]. Aluminosilicate gel was prepared by mixing freshly prepared aluminate and silicate solutions at a molar ratio of 5.5 $\mathrm{Na}_{2} \mathrm{O}: 1.0 \mathrm{Al}_{2} \mathrm{O}_{3}: 4.0 \mathrm{SiO}_{2}: 190 \mathrm{H}_{2} \mathrm{O}$. In a typical synthesis, sodium hydroxide solution ( $5.34 \mathrm{~g}$ of $\mathrm{NaOH} / 50 \mathrm{~mL}$ of $\mathrm{H}_{2} \mathrm{O}$ ) was freshly prepared, followed by addition of $2.42 \mathrm{~g}$ of sodium aluminate

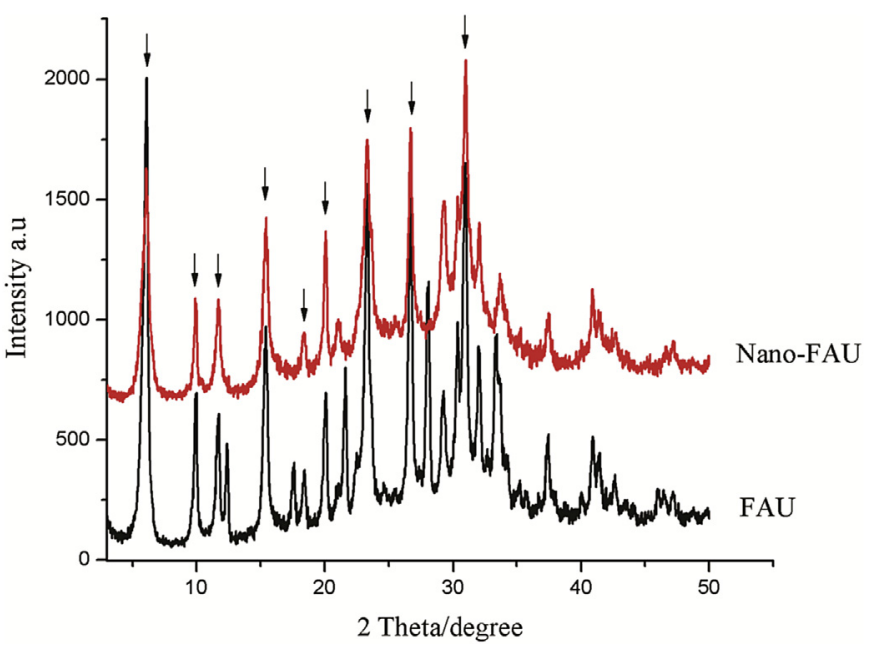

Fig. 1. XRD patterns of the as made micrometric (FAU) and nanometric faujasite zeolite (Nano-FAU).

$\left(\mathrm{NaAlO}_{2}\right)$, with stirring for $15 \mathrm{~min}$ at room temperature. Fumed silica $\left(\mathrm{SiO}_{2}, 3.43 \mathrm{~g}\right)$ was then added to the solution, with stirring until a homogeneous gel was obtained. The gel was immediately transferred to a temperature-controlled shaker and agitated at $250 \mathrm{rpm}$ for 2 days at $60{ }^{\circ} \mathrm{C}$. The powdered product was recovered by centrifugation at 13,400 rpm (CR22N centrifuge, Hitachi, Tokyo, Japan), washed with deionized water until reaching $\mathrm{pH}<8$, and dried in an oven at $40{ }^{\circ} \mathrm{C}$ for $16 \mathrm{~h}$. The micrometric faujasite zeolite was synthesized following the same procedure described above, except that crystallization was conducted at $90{ }^{\circ} \mathrm{C}$ for 4 days in a static reactor (Parr Instruments Co., USA). The micrometric and nanometric zeolites were denoted FAU and Nano-FAU, respectively.

\subsubsection{Ion exchange of the zeolite}

In a typical ion exchange experiment [27], $1 \mathrm{~g}$ portions of asmade FAU and Nano-FAU were added to several Teflon-lined digestion reactors (Parr Instruments Co., USA), followed by the addition of $30 \mathrm{~mL}$ of $0.5 \mathrm{M} \mathrm{CaCl}_{2}$ solution to each reactor. The ion exchange reactions were conducted at $90{ }^{\circ} \mathrm{C}$ for $12 \mathrm{~h}$. The solid products were subsequently collected by centrifugation at 13,400 rpm, washed three times with deionized water, and dried in an oven at $40{ }^{\circ} \mathrm{C}$ for $16 \mathrm{~h}$. The ion exchanged zeolite derivatives were denoted FAU/Ca (micrometric) and Nano-FAU/Ca (nanometric).

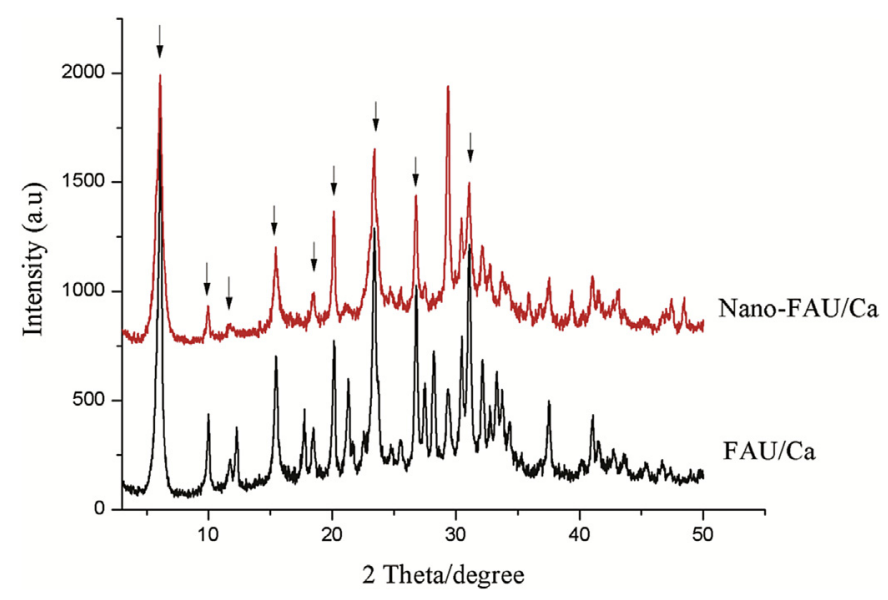

Fig. 2. XRD patterns of the calcium-exchange derivatives (FAU/Ca; Nano-FAU/Ca). 

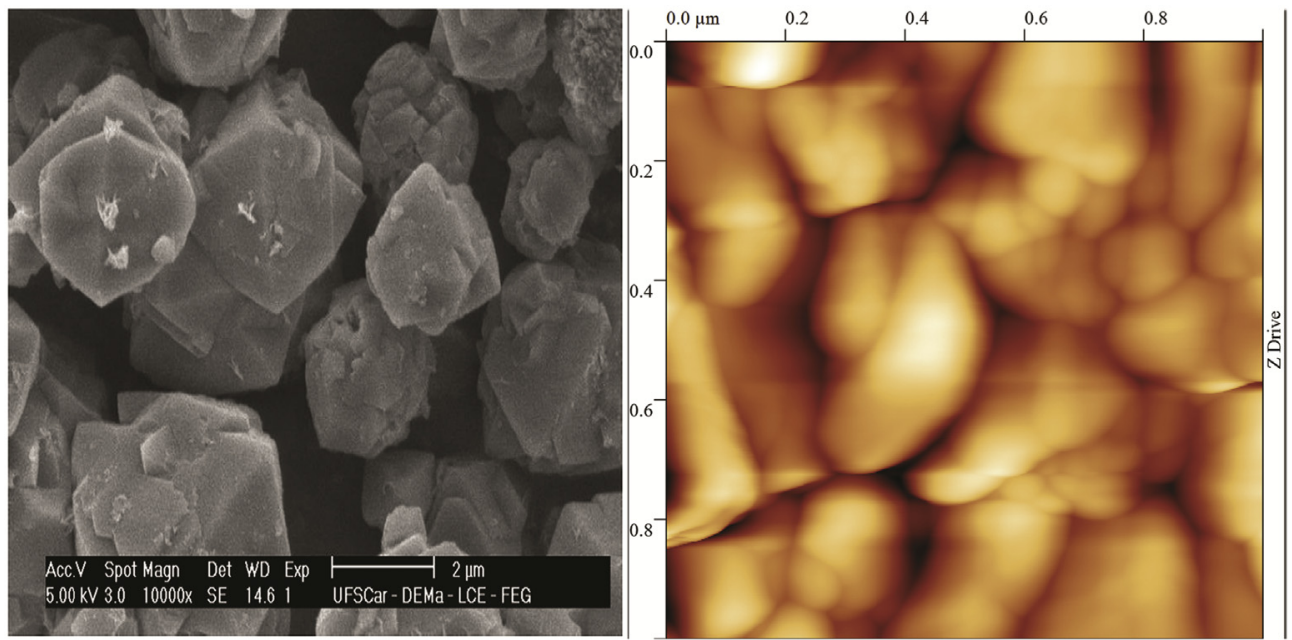

Fig. 3. SEM/AFM micrographs of the as made micrometric faujasite zeolite (FAU).

\subsection{Physical characterization of the micrometric and nanometric} faujasite zeolites

The as-made and calcium exchanged zeolites were characterized by XRD, SEM, AFM, TGA, and DSC. The XRD analyses were performed using a MiniFlex II instrument (Rigaku, Tokyo, Japan) with a rotating anode source, flat-plate Bragg-Brentano geometry, and a graphite monochromator. The instrument was operated with $\mathrm{CuK} \alpha$ radiation (wavelength $=1.5418 \AA$ ) at $40 \mathrm{kV}$ and $15 \mathrm{~mA}$. The powder diffraction patterns were recorded in the range $2 \theta=3-50^{\circ}$, with a goniometer scan rate of $2^{\circ}(2 \theta) \mathrm{min}^{-1}$. The AFM and SEM analyses were performed at the Brazilian National Laboratory of
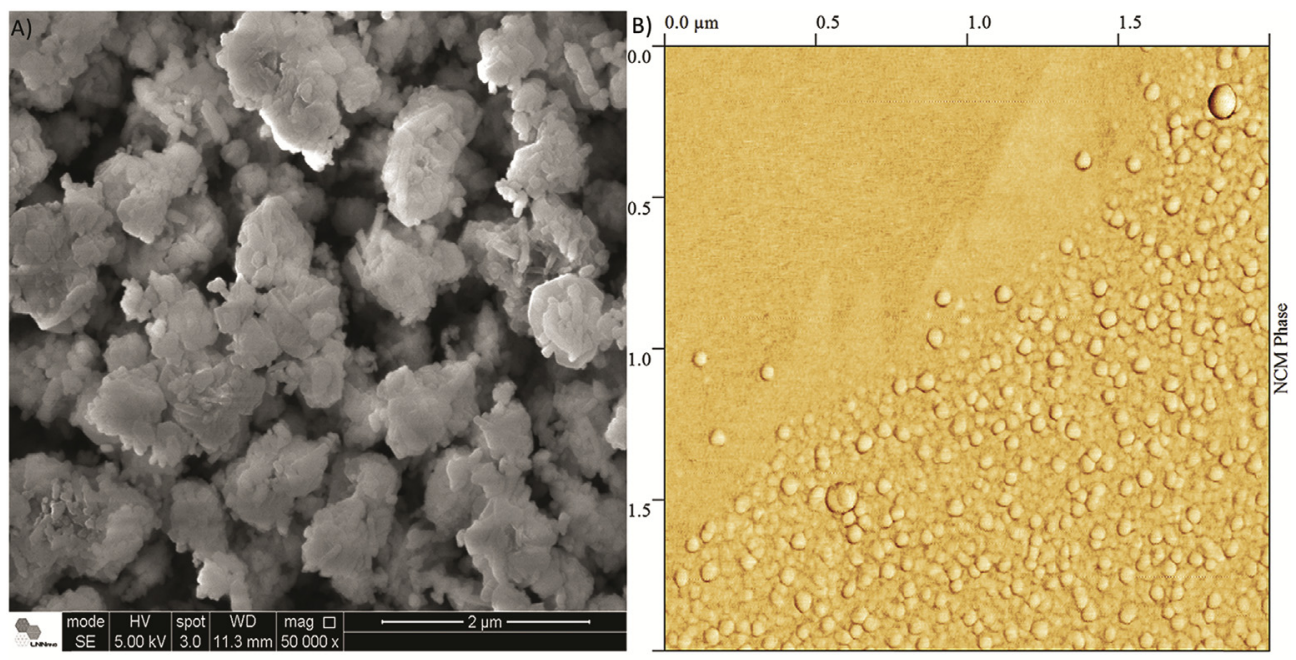

C)

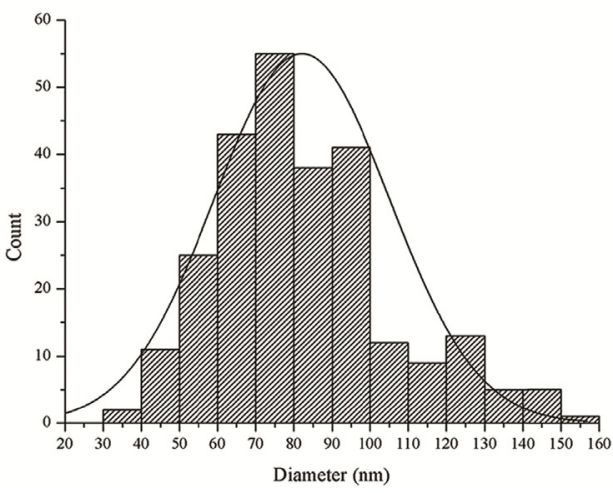

Fig. 4. SEM/AFM micrographs and size distribution of the of the as made nanometric faujasite zeolite (Nano-FAU). 

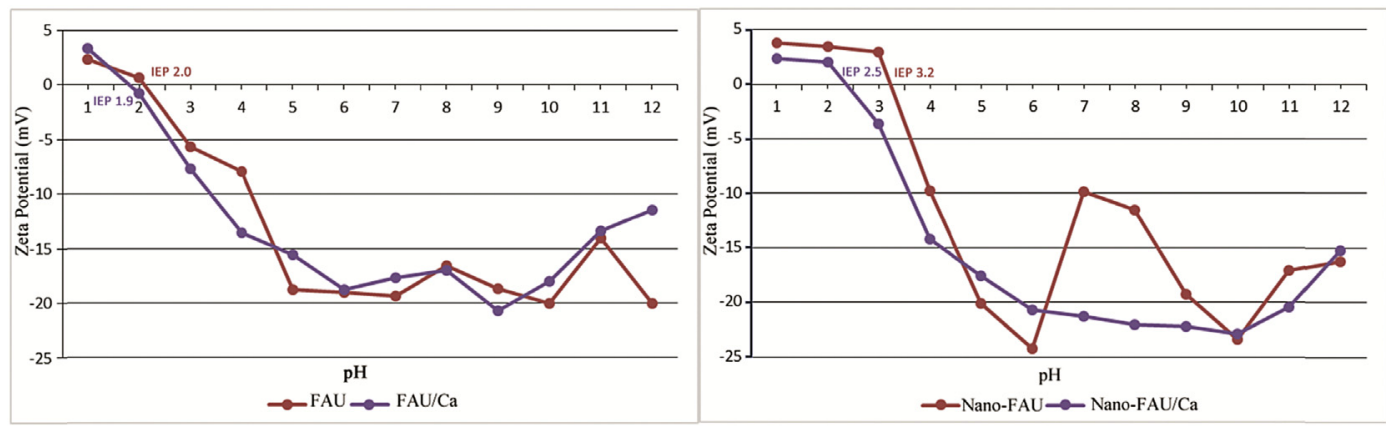

Fig. 5. Zeta potential in function $\mathrm{pH}$ of as made micrometric faujasite zeolite (FAU) and nanometric (Nano-FAU) and calcium-exchange derivates (FAU/Ca; Nano-FAU/Ca).

Nanotechnology (LNNano) in Campinas. The AFM experiments employed an NX-10 microscope (Park Systems, Suwon, Korea) fitted with a PPP-NCHR probe, operated at $320 \mathrm{kHz}$ resonance frequency and constant force of $42 \mathrm{~N} / \mathrm{m}$. Tapping mode AFM images were acquired in ambient air using TESP tapping mode etched silicon probes. SEM data were obtained using an XL30 FEG instrument (Philips, Eindhoven, The Netherlands), with a thin coating of gold deposited onto the samples prior to analysis and particle size distribution analysis was performed using Image Pro plus ${ }^{\circledR}$ software. Elemental chemical analyses of nanosized faujasite were performed via inductively coupled plasma atomic emission spectroscopy (ICP-AES, Chemical Analysis Labs-Sao Paulo University Facilities-USP).

Phase contrast imaging was performed using a BX60 microscope (Olympus, New York, USA). In these analyses, $170 \mu \mathrm{L}$ volumes of whole blood, collected in tubes containing sodium citrate $(4 \% \mathrm{v} / \mathrm{v})$, were deposited onto glass microscope slides. Then, $10 \mu \mathrm{L}$ of $0.2 \mathrm{M}$ aqueous $\mathrm{CaCl}_{2}$ was added to the blood to reverse the anticoagulant effect caused by calcium chelation. After this, $0.25 \mathrm{mg}$ portions of each micrometric and nanometric faujasite zeolite and their ion exchanged derivatives were deposited under the blood. The slide was immediately placed in the microscope for assessment of the structures formed.

\subsubsection{Thermal gravimetric analysis (TGA) and differential scanning calorimetry (DSC)}

Thermal gravimetric analysis (TGA) and differential scanning calorimetry (DSC) were performed according to the methodologies described by Ostomel et al. [24], Drebushchak [28] and Brown [29]. The as-made and calcium exchanged zeolites were stored for two weeks in enclosures suspended over a Petri dish containing a saturated water solution of $\mathrm{KBr}$, which maintains $80 \%$ relative humidity. Thermal analyses (DSC/TG) were performed using a Netzsch 429 instrument (Selb, Germany) which was used to quantify the heat associated with the desorption of water from the zeolite. The synthesized materials $(5 \mathrm{mg}$ ) were heated in a stream of synthetic air $(50 \mathrm{~mL} / \mathrm{min})$ at a heating rate of $10{ }^{\circ} \mathrm{C} / \mathrm{min}$ in the temperature range $25-500{ }^{\circ} \mathrm{C}$. The hydration capacity of each zeolite was measured by thermogravimetric analysis (TGA) of water loss, and simultaneously collected differential scanning calorimetric (DSC) curves were integrated to obtain the total heat for the dehydration reaction.

\subsubsection{Isoelectric point determination (zeta potential)}

The isoelectric points (IEP) (which is defined as the $\mathrm{pH}$ at which the total of negative and positive surface charges equals zero) were estimated using zeta potential data obtained with a Malvern NanoZS instrument (Malvern Instruments, Herrenberg, Germany), following the procedure described by Ostomel et al. [30]. Zeta potential of synthesized material were measured as a function of $\mathrm{pH}$ using Smoluchowski's equation [31].

The purpose of this experiment was to understand how the anticoagulant or procoagulant properties of the zeolite varied according to the $\mathrm{pH}$ of the isoelectric point. Approximately $2 \mathrm{mg}$ portions of the as-made and calcium exchanged zeolites were suspended in $60 \mathrm{~mL}$ of aqueous $0.03 \mathrm{M} \mathrm{CaCl}_{2}$ and sonicated for 10 min before analysis. Zeta potential measurements of the suspensions were conducted as a function of $\mathrm{pH}$ in the range 1-12.5, which was adjusted by the addition of $0.25 \mathrm{M} \mathrm{HCl}$ or $\mathrm{NaOH}$ solutions. Due to the heterogeneous colloidal nature of blood, it is impossible to measure the zeta potential of the zeolite in situ, so the surface charge must be inferred from the electrophoretic mobility measurements $[30,32]$. The experiment was performed in the presence of a $\mathrm{CaCl}_{2}$ electrolyte that mimicked the calcium ion concentrations found in blood serum [30].

\subsubsection{Thromboelastography analysis (TEG)}

Thromboelastography was performed using a Haemonetics TEG 5000 thromboelastograph (Niles, IL, USA), with volunteers who were physically healthy and had no history of blood disorders. This analysis was used to acquire in vitro clotting parameters for total blood stabilized with sodium citrate $(4 \% \mathrm{v} / \mathrm{v})$ and exposed to the hemostatic materials evaluated. Firstly, $20 \mu \mathrm{L}$ of $0.2 \mathrm{M}$ aqueous $\mathrm{CaCl}_{2}$ was added to $340 \mu \mathrm{L}$ of the whole blood, followed by direct introduction of $0.5 \mathrm{mg}$ of hydrated micrometric and nanometric faujasite zeolite into the TEG sample cup containing the blood and performance of the measurement.

\subsubsection{Statistical analysis}

The descriptive statistical analysis for evaluation of the micrometric and nanometric faujasite zeolites and their calcium exchanged derivatives (control, FAU, FAU/Ca, Nano-FAU, and NanoFAU/Ca) was performed using averages and standard deviations. For inferential statistical analysis, the average values for each group were compared using one-way ANOVA (with a significance level of $\mathrm{p} \leq 0.05$ ). When statistically significant differences were detected,

Table 1

Summary of the parameters analyzed in thromboelastography of micrometric and nanometric faujasite zeolite and its calcium-exchange derivative: Control; FAU; FAU/Ca; Nano-FAU and Nano-FAU/Ca.

\begin{tabular}{lllll}
\hline Sample & $\mathrm{R}(\mathrm{min})$ & $\mathrm{K}(\mathrm{min})$ & Alpha angle $\left(^{\circ}\right)$ & $\mathrm{MA}(\mathrm{mm})$ \\
\hline Control $^{\mathrm{a}}$ & $8.6 \pm 0.7$ & $3.5 \pm 0.7$ & $49.7 \pm 7.5$ & $53.6 \pm 2.6$ \\
FAU & $3.2 \pm 0.7$ & $1.2 \pm 0.1$ & $74.3 \pm 1.0$ & $64.0 \pm 0.9$ \\
FAU/Ca & $2.3 \pm 0.1$ & $1.2 \pm 0.1$ & $75.6 \pm 1.2$ & $55.5 \pm 5.0$ \\
Nano-FAU & $2.4 \pm 0.6$ & $1.2 \pm 0.1$ & $73.9 \pm 2.3$ & $61.2 \pm 2.3$ \\
Nano-FAU/Ca & $1.1 \pm 0.2$ & $1.2 \pm 0.1$ & $75.1 \pm 2.3$ & $60.3 \pm 1.6$ \\
\hline
\end{tabular}

Blood not exposed to the hemostatic agents. 


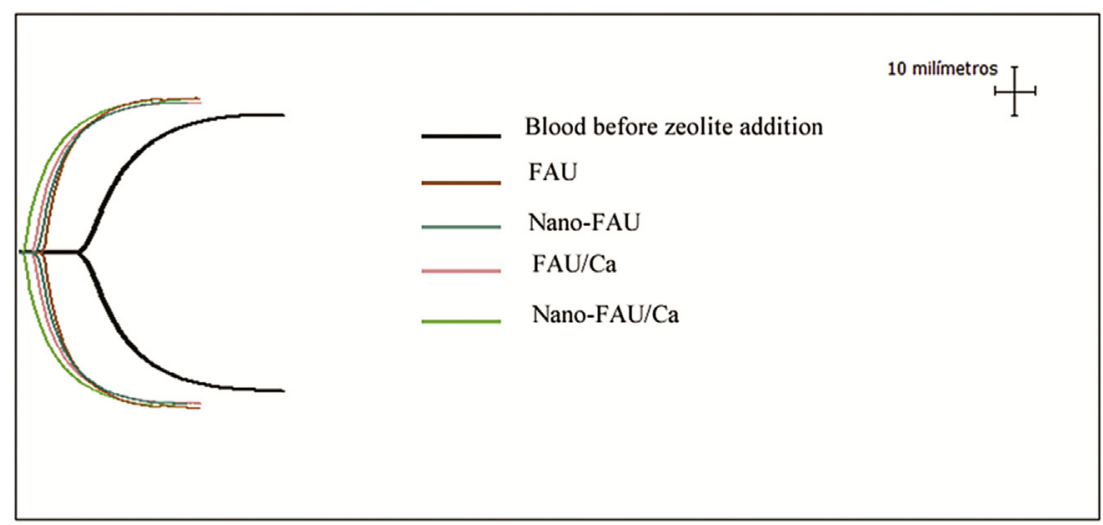

Fig. 6. Thromboelastography plot of the blood before zeolite addition and after addition of FAU; Nano-FAU; FAU/Ca and Nano-FAU/Ca.

multiple comparisons were performed using the Tukey-Kramer post-test.

\section{Results and discussion}

XRD patterns of the as made FAU and Nano-FAU and their calcium ion-exchanged derivatives FAU/Ca and Nano-FAU/Ca are respectively shown in Figs. 1 and 2. XRD data for the as made micro and nanometric faujasite zeolites are in accordance with results reported by Zhan et al. [26] and ICP-AES revealed a Si/Al ratio of 1.40 , which by definition is a NaX faujasite [33]. Typical Bragg reflections for micrometric and nanometric faujasite zeolites were observed at $\left(2 \theta=6.1^{\circ}, 9.8^{\circ}, 11.7^{\circ}, 12.3^{\circ}, 15.3^{\circ}, 20^{\circ}, 21.6^{\circ}\right.$, $\left.23.3^{\circ}, 26.6^{\circ}, 28^{\circ}, 31.1^{\circ}, 33.3^{\circ}\right)$ XRD patterns of the calciumexchange derivatives have caused no significant modification of the structure in comparison to the original micro and nanometric zeolites (Fig. 2).

SEM and AFM micrographs of the as made micro and nanometric faujasite (FAU; NanoFAU) are shown in Figs. 3 and 4 respectively. Crystal morphology of micrometric faujasite is built up of hexagonal shaped crystals whose size range from 1 to $3 \mu \mathrm{m}$, while SEM micrographs for nanometric zeolites show agglomerated crystal with particle size in the $60-100 \mathrm{~nm}$ range (Fig. 4c). The ion-exchange process with calcium have caused no significant difference in the morphology of micrometric or nanometric zeolites.
A)

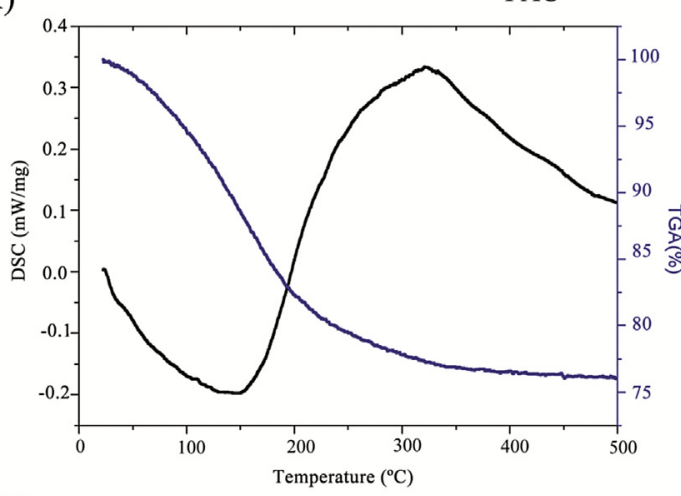

C)

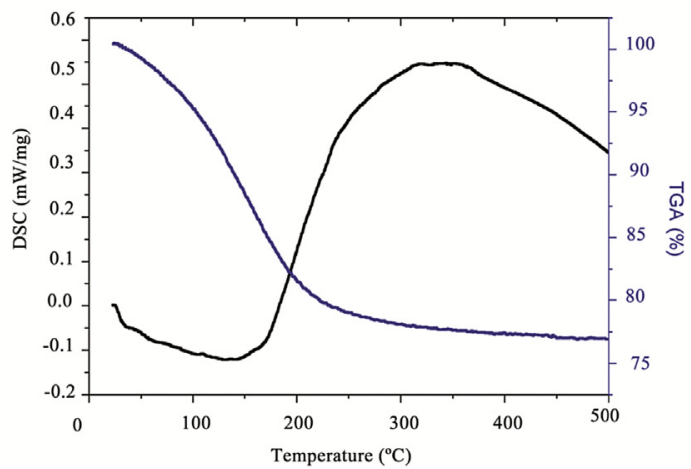

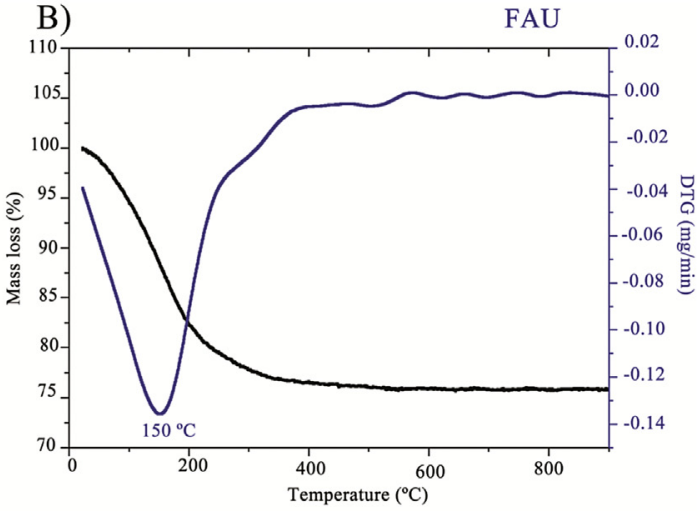

D)

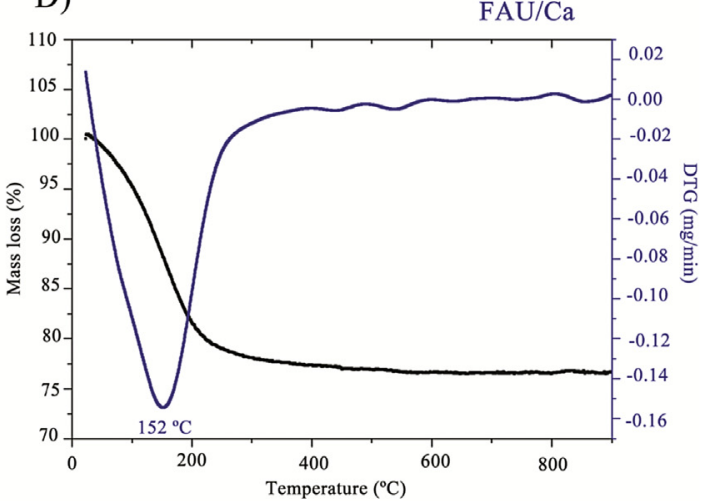

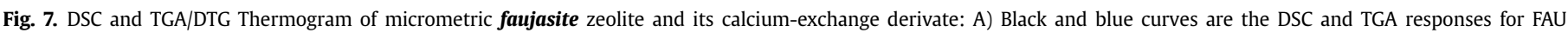

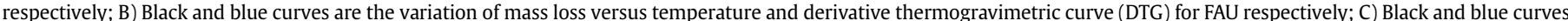

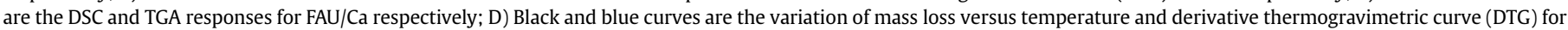
FAU/Ca respectively. (For interpretation of the references to colour in this figure legend, the reader is referred to the web version of this article.) 
A)

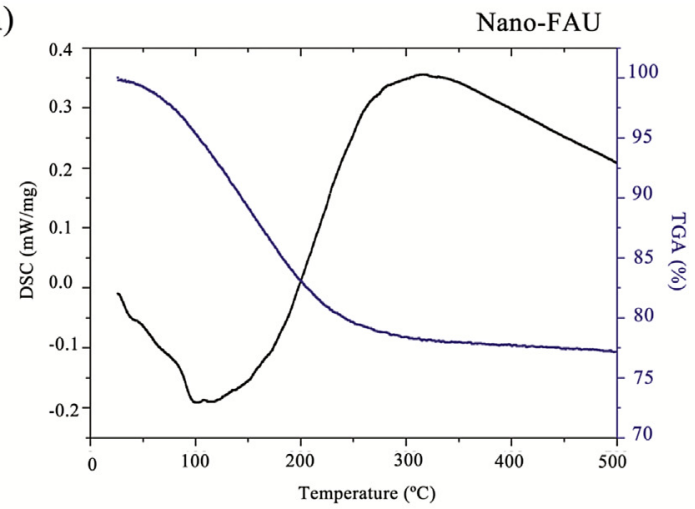

C)

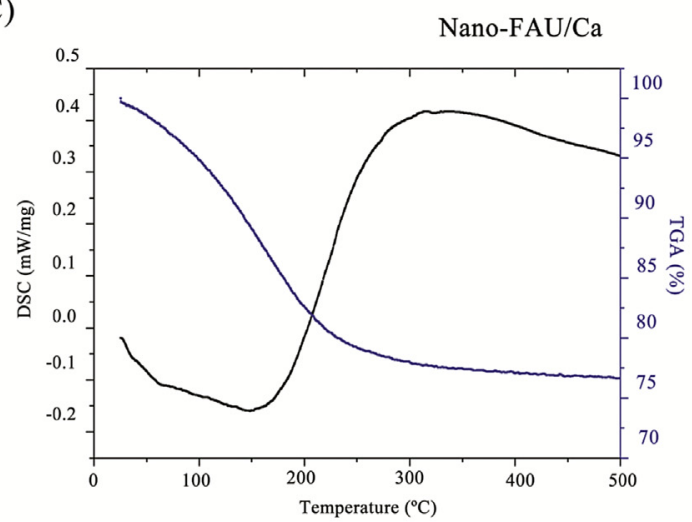

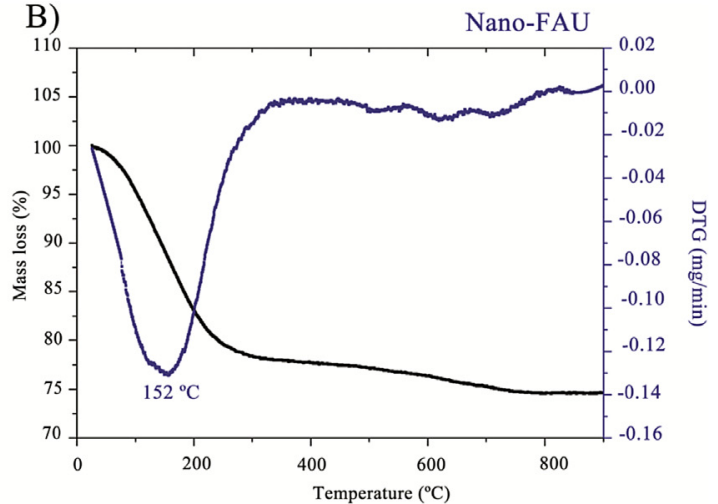

D)

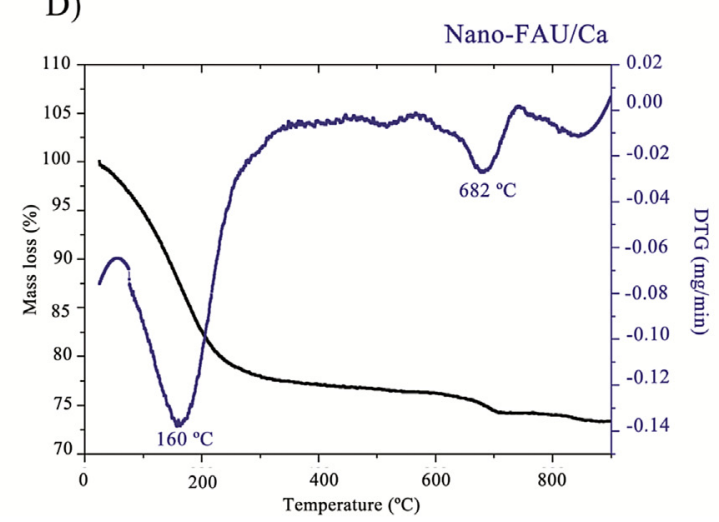

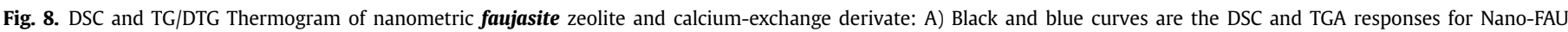

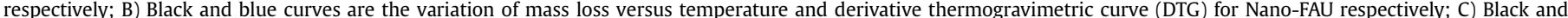

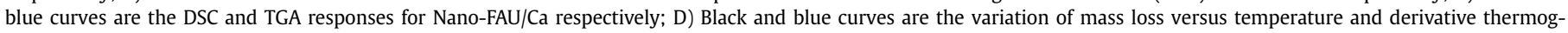

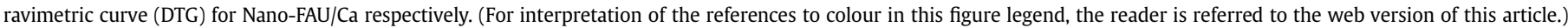

The zeta potential of zeolites can be positive or negative and it depends not only on the $\mathrm{pH}$, but also on the ionic strength of the suspension, the presence of organic templates or structure directing agents (SDAs) and the Al content of the framework [34]. As pointed out by Griffin et al. [35], zeolites can act as surface contact activation agents due to their negative surface charges, by rendering factor XII (FXII) much more susceptible to proteolysis activation by the kallikrein protein, therefore it is important follow the surface charge behavior of zeolites.

Zeolite structures are defined by the numbers of silanol and aluminol groups present at the crystal surface, and these groups can be easily deprotonated to form $\mathrm{SiO}^{-}$and $\mathrm{AlO}^{-}$, in a wide $\mathrm{pH}$ range, hence making the surface more negatively charged [36,37]. On the other hand, a lower $\mathrm{pH}$ leads to protonation, so the surface charge tends to be positive and the isoelectric point is reached. Fig. 5 shows the experimental isoelectric points for micrometric (FAU) and nanometric (Nano-FAU) faujasite zeolites and their calcium-exchange derivatives (FAU/Ca; Nano-FAU/Ca). Detailed experimental zeta potential $(\mathrm{mV})$ as a function of the $\mathrm{pH}$ are provided in the supplementary material.

The isoelectric point of a metal oxide is an important parameter because it can strongly affect the biological response during activation of the coagulation cascade reactions [30]. According to Ostomel et al. [30], basic oxides with isoelectric points above the $\mathrm{pH}$ of blood (7.3-7.4) and which are initially positively charged when immersed in blood are, in principle, anticoagulant oxides. On the other hand, acidic oxides with isoelectric points below the physiological $\mathrm{pH}$ of blood, which initially carry negative charges when immersed in blood, are procoagulant oxides.
Experimental $\mathrm{pH}$ value for isoelectric points (IEP) of the zeolite samples were 2.0, 1.9, 3.2, 2.5 for FAU, FAU/Ca, Nano-FAU, Nano$\mathrm{FAU} / \mathrm{Ca}$, respectively. It is was observed that all samples showed the isoelectric point below the blood $\mathrm{pH}(7.3-7.4)$, therefore all the samples are procoagulants. It is important to observe that in the $3.2<\mathrm{pH}<12.5 \mathrm{pH}$ range the zeolite surface remained negatively charged and no isoelectric point was observed in this $\mathrm{pH}$ range. Although in this work we can not provide straightforward experimental evidence of it, some authors have in principle associated the zeolite surface charges as resulting of the surface silanol groups deprotonation [38] and or to the protonation or dissociation of the hydroxyl groups according to scheme described below [36]:

$$
\begin{gathered}
\mathrm{SiOH}_{2}^{+} \underset{+}{\stackrel{\mathrm{H}^{+}}{\rightleftarrows}} \mathrm{SiOH} \underset{+}{\stackrel{\mathrm{H}^{+}}{\rightleftarrows}} \mathrm{SiO}^{-} \\
\mathrm{AlOH}_{2}^{+} \underset{+}{\stackrel{\mathrm{H}^{+}}{\rightleftarrows}} \mathrm{AlOH} \underset{+}{\stackrel{\mathrm{H}^{+}}{\rightleftarrows}} \mathrm{AlO}^{+}
\end{gathered}
$$

The in vitro hemostatic activities of the zeolitic materials were evaluated using the thromboelastography technique, which provides a global evaluation of hemostasis by quantitatively measuring the viscoelastic changes in blood during the coagulation process, from the beginning to the final [39].

Experimental relevant parameters for the clotting process are: $\mathrm{R}$ (as the period of time of latency from the start of test to initial fibrin formation for the formation of a clot of an amplitude of $2 \mathrm{~mm}$ ) 


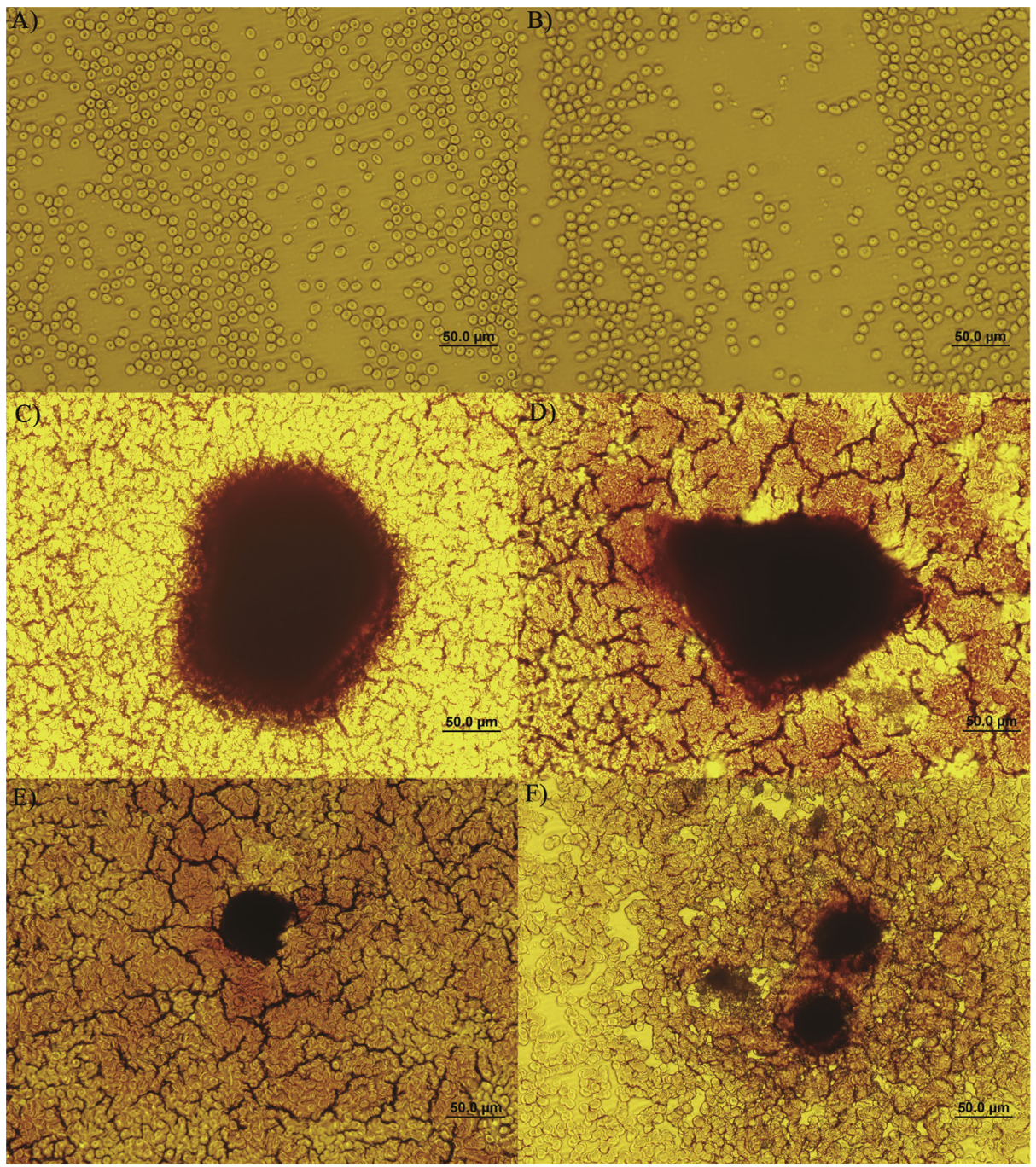

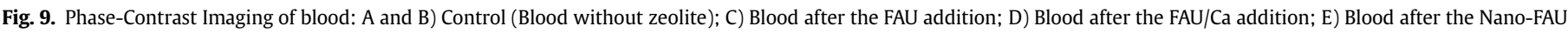
addition and F) Blood after the Nano-FAU/Ca addition.

[40,41]; $\mathrm{K}$ (time for the clot size to reach $20 \mathrm{~mm}$ ); $\alpha$ angle (inclination between $\mathrm{R}$ and $\mathrm{K}$, representing the rate of thrombin generation and the conversion of fibrinogen to fibrin); and MA (maximum amplitude, reflecting the maximum elastic property of fibrin and platelet adhesion) [39]. These parameters were measured for all the zeolite samples and are summarized in Table 1 and their thromboelastogram plots are shown in Fig. 6.

The use of FAU resulted in decreases of the values of $\mathrm{R}$ and $\mathrm{K}$ from $8.6 \pm 0.7 \mathrm{~min}$ (control) to $3.2 \pm 0.7 \mathrm{~min}$, and from $3.5 \pm 0.7 \mathrm{~min}$ to $1.2 \pm 0.1 \mathrm{~min}$, respectively. The $\alpha$ angle and MA values increased from $49.7 \pm 7.5^{\circ}$ to $74.3 \pm 1.0^{\circ}$, and from $53.6+2.6 \mathrm{~mm}$ to $64.0+0.9 \mathrm{~mm}$, respectively. In the case of FAU/ $\mathrm{Ca}, \mathrm{R}$ decreased from $3.2 \pm 0.7 \mathrm{~min}$ (FAU) to $2.3 \pm 0.1 \mathrm{~min}$ (FAU/Ca). No noticeable or significant differences in the $\mathrm{K}$ and $\alpha$ angle parameters were observed between FAU and FAU/Ca (Table 1). However, the MA value was smaller for FAU/Ca $(55.5 \pm 5.0 \mathrm{~mm})$ than for FAU $(64.0 \pm 0.9 \mathrm{~mm})$. There was a significant decrease in $\mathrm{R}$ for Nano-FAU/Ca $(1.1 \pm 0.2 \mathrm{~min})$, compared to Nano-FAU $(2.4 \pm 0.6 \mathrm{~min})$. Considering the other parameters, there were no significant differences between Nano/FAU and Nano-FAU/Ca (Table 1). The application of one-way analysis of variance resulted in a global $\mathrm{p}$ value $<0.0001$, and use of the Tukey-Kramer multiple comparisons test revealed significant $(p<0.0001)$ differences for FAU, FAU/Ca, Nano-FAU, and Nano-FAU/Ca, relative to the control. Nano-FAU/Ca showed the greatest reductions of the $\mathrm{R}$ and $\mathrm{K}$ values, with significant differences compared to the control ( $\mathrm{p}<0.0001$ and $\mathrm{p}<0.0001$, respectively) and FAU ( $\mathrm{p}=0.0071$ for the $\mathrm{R}$ parameter $)$.

It is clear from the results that the all the zeolites here investigated were potential hemostatic coagulant agents, nevertheless in the design of hemostatic agents for medical devices the $R$ parameter is critical, because a rapid clotting is the essential first response in a medical emergency. Ostomel et al. [30] reported that materials that could induce a detectable blood clot in 2 min in vitro correlated with a $75 \%$ survivability when applied externally as a rapidly-acting hemostatic agent to a universally lethal injury of the vascular system [17,42]. In this study, significant reductions in the $\mathrm{R}$ time were observed, especially with the nanometric calcium exchanged faujasite derivative (Nano-FAU/ Ca), strongly indicating that Nano-FAU/Ca should act as an efficient hemostatic agent. Hence, it was experimentally shown that zeolite size plays an important role in the coagulation cascade (see Table 1 and Fig. 6).

$\mathrm{Ca}^{2+}$ ions are essential cofactors that are vital for the orientation of clotting enzymes on cellular surfaces, providing ionic bridges between two negatively charged residues (such as cellular 
surfaces and clotting factors) [42,43]. Li et al. [44], using Quikclot ${ }^{\circledR}$ ion exchanged with $\mathrm{Ca}^{2+}$, reported that $\mathrm{Ca}^{2+}$ ions maintained the procoagulant activity of zeolites. However, the zeolite used was on the micrometric scale and no thromboelastography parameters ( $R, K, \alpha$ angle, or MA) were measured, only the qualitative prothrombin time (PT) and the activated partial thromboplastin time (APTT).

Side effects of using zeolites as hemostatic agents, such as hightemperature exothermic reactions due to water adsorption, have been extensively discussed in the literature $[3,22,45,46]$, and in order to know if the zeolite scale could have some influence on this parameters DSC/TG analyses were performed. The heat of hydration for synthetized materials was calculated by integrating the DSC response whereas the water content in the zeolite is measured experimentally as mass loss versus temperature and the derivative thermogravimetric curve (DTG) which expresses the first derivative of the mass variation versus time as a function of temperature. These results are shown in Figs. 7 and 8. Experimental DSC/TGA data revealed significantly lower energy release for the nanometric faujasite Nano-FAU $(85.48 \mathrm{~J} / \mathrm{g})$, compared to the micrometric zeolite FAU (105.6 J/g). Furthermore, the ion exchanged materials showed lower energy release, with values of 105.60 and $65.8 \mathrm{~J} / \mathrm{g}$ obtained for FAU and FAU/Ca, respectively. Experimental values of 85.48 and $78.21 \mathrm{~J} / \mathrm{g}$ were observed for Nano-FAU and Nano-FAU/Ca, respectively. Therefore, in principle, Nano-Fau/Ca should not only be the best hemostatic agent (according to the thromboelastography parameters), but should also have less severe side effects in terms of burning.

According to the results reported by Ostomel et al. [24], zeolite Linde Type 5A ion exchanged with monovalent cations $\left(\mathrm{K}^{+}, \mathrm{Ag}^{+}\right)$ are more efficient in reducing the heat releasing than divalent cations $\left(\mathrm{Ba}^{2+}, \mathrm{Sr}^{2+}\right)$. Zeolite Linde type $5 \mathrm{~A}$ ion exchanged with $\mathrm{K}^{+}$ and $\mathrm{Ag}^{+}$have caused a decrease of heat release from $680 \mathrm{~J} / \mathrm{g}$ to $584 \mathrm{~J} / \mathrm{g}$ and $420 \mathrm{~J} / \mathrm{g}$, respectively. While ion exchange with $\mathrm{Ba}^{2+}$ and $\mathrm{Sr}^{2+}$ have caused a decrease of heat release from 680 to $600 \mathrm{~J} /$ $\mathrm{g}$ and $650 \mathrm{~J} / \mathrm{g}$, respectively. Therefore replacement of $\mathrm{Na}^{+}$ions for different monovalent or divalent ions has the potential of decreasing the energy loss or heat releasing of these materials. Our data shown that the replacement of $\mathrm{Na}^{+}$ions for $\mathrm{Ca}^{2+}$ has also caused decreased the heat releasing from 105.6 to $65.8 \mathrm{~J} / \mathrm{g}$. One possible explanation to this significant difference between the values found by Ostomel et al. [24] and results reported in this work could attributed to the their different zeolites crystallographic structures of the zeolites [47,48]. Both zeolites have a completely different system of channels and porous with crystallographic or occupation site defined by distinct space groups and symmetries [49], hence it is reasonable to expect that the extra-framework cations would have different diffusion and physicochemical behavior at the distinct crystallographic sites by binding themselves strong or weakly to the crystallographic waters molecules or framework oxygen, therefore in order to break down these chemical bonds different amount of energy would be required.

Additionally phase-contrast microscopy was also performed in order to observe the morphological changes in red cells when zeolites come into contact with blood. Fig. 9a and b have shown red cells before the addition of zeolite using a phase contrast objective with an increase of $10 \mathrm{X}$ and the data reveal that normal red blood cells have a circular shape, biconcave format and have a diameter ranging from 6 to $8 \mu \mathrm{m}$ in absence of zeolites. The presence of zeolite cause a red cell agglomeration forming a large clot similar to a mass solid blood cells (Fig. 9c-f). Similar behavior was also observed for micrometric faujasite zeolite calcium-exchange derivative FAU/Ca (Fig. 9d); Nano-FAU (Fig. 9e) and Nano-FAU/Ca (Fig. 9f) were put in contact with blood, therefore confirming the clot formation and the capacity of zeolites to promote the acceleration of blood coagulation.

\section{Conclusions}

Experimental evidences have shown that nanometric faujasite zeolites are more efficient hemostatic agents in comparison to the micrometric zeolites, therefore with potential of being externally used as rapidly-acting hemostatic agent to a universally lethal injury of the vascular system. The use of in vitro assays with micrometric and nanometric zeolites have shown Nano-FAU and Nano-FAU/Ca have significantly induced the formation of a detectable blood clot faster than the micrometric zeolites. Nanometric zeolites materials in principle can also reduce the collateral damage of burning, since the experimental evidences have shown they released lesser heat than the micrometric zeolites.

\section{Acknowledgements}

This work was funded by the São Paulo State Research Foundation (FAPESP, \#2013/16754-4, \#2012/24259-0), and made use of the CNPEM/LNNano (National Research Center for Energy and Materials) facilities (\#SEM-19234/AFM-17388).

\section{Appendix A. Supplementary data}

Supplementary data related to this article can be found at http:// dx.doi.org/10.1016/j.micromeso.2016.10.020.

\section{References}

[1] G.C. Velmahos, M. Tabbara, K. Spaniolas, M. Duggan, H.B. Alam, M. Serra, L. Sun, J. de Luis, J. Trauma 66 (2009) 984-988.

[2] I. Wedmore, J.G. McManus, A.E. Pusateri, J.B. Holcomb, J. Trauma 60 (2006) 655-658.

[3] H.B. Alam, Z. Chen, A. Jaskille, R. Querol, E. Koustova, R. Inocencio, R. Conran, A. Seufert, N. Ariaban, K. Toruno, P. Rhee, J. Trauma 56 (2004) 974-983.

[4] J. Granville-Chapman, N. Jacobs, Injury 42 (2011) 447-459.

[5] B.G. Kozen, S.J. Kircher, J. Henao, F.S. Godinez, A.S. Johnson, Acad. Emerg. Med.; Off. J. Soc. Acad. Emerg. Med. 15 (2008) 74-81.

[6] M. Wu, Z. Ye, H. Zhu, X. Zhao, Biomacromolecules 16 (2015) 3112-3118.

[7] D.G. Wallace, G.M. Cruise, W.M. Rhee, J.A. Schroeder, J.J. Prior, J. Ju, M. Maroney, J. Duronio, M.H. Ngo, T. Estridge, G.C. Coker, J. Biomed. Mater. Res. 58 (2001) 545-555.

[8] E. Huri, T. Akgül, A. Ayyıldız, H. Üstün, C. Germiyanoğlu, J. Urol. 181 (2009) 2349-2354.

[9] Y.L. Zhang, C. Xu, Y.Q. He, X.D. Wang, F.B. Xing, H.X. Qiu, Y. Liu, D.Y. Ma, T. Lin, J.P. Gao, J. Biomater. Sci. Polym. 22 (2011) 809-822.

[10] T. Gerlach, J.K. Grayson, K.O. Pichakron, M.J. Sena, S.D. DeMartini, B.Z. Clark J.S. Estep, D. Zierold, J. Trauma 69 (2010) 1203-1209.

[11] B.S. Kheirabadi, M.R. Scherer, J.S. Estep, M.A. Dubick, J.B. Holcomb, J. Trauma Acute Care Surg. 67 (2009) 450-460.

[12] B.S. Kheirabadi, J.E. Mace, I.B. Terrazas, C.G. Fedyk, J.S. Estep, M.A. Dubick L.H. Blackbourne, J. Trauma Acute Care Surg. 68 (2010) 269-278.

[13] S.E. Baker, A.M. Sawvel, N. Zheng, G.D. Stucky, Chem. Mater. 19 (2007) 4390-4392.

[14] T. Peng, Biomater. Artif. Organs 24 (2010) 27-68.

[15] A.E. Pusateri, J.B. Holcomb, B.S. Kheirabadi, H.B. Alam, C.E. Wade, K.L. Ryan, J. Trauma 60 (2006) 674-682.

[16] P. Rhee, C. Brown, M. Martin, A. Salim, D. Plurad, D. Green, L. Chambers, D. Demetriades, G. Velmahos, H. Alam, J. Trauma 64 (2008) 1093-1099.

[17] N. Ahuja, T.A. Ostomel, P. Rhee, G.D. Stucky, R. Conran, Z. Chen, G.A. AlMubarak, G. Velmahos, M. deMoya, H.B. Alam, J. Trauma 61 (2006) $1312-1320$.

[18] H.E. Achneck, B. Sileshi, R.M. Jamiolkowski, D.M. Albala, M.L. Shapiro, J.H. Lawson, Ann. Surg. 251 (2010) 217-228.

[19] H.B. Alam, D. Burris, J.A. DaCorta, P. Rhee, Mil. Med. 170 (2005) 63-69.

[20] S.M.J. Mortazavi, A. Tavasoli, M. Atefi, N. Tanide, N. Radpey, P. Roshan-shomal, H. Moradi, S. Taeb, World J. Emerg. 4 (2013) 123-127.

[21] M. Alavi, A. Totonchi, M.A. Okhovat, M. Motazedian, P. Rezaei, M. Atefi, Blood Coagul. Fibrinolysis; Int. J. Haemost. Thromb. 25 (2014) 856-859.

[22] J.K. Wright, J. Kalns, E.A. Wolf, F. Traweek, S. Schwarz, C.K. Loeffler, W. Snyder L.D. Yantis, J. Eggers, J. Trauma 57 (2004) 224-230.

[23] T.R. Hurtado, T. Wisenbaugh, Ann. Emerg. Med. 46 (2005) 297. 
[24] T.A. Ostomel, P.K. Stoimenov, P.A. Holden, H.B. Alam, G.D. Stucky, J. Thromb. Thrombolysis 22 (2006) 55-67.

[25] L. Tosheva, V.P. Valtchev, Chem. Mater. 17 (2005) 2494-2513.

[26] B.Z. Zhan, M.A. White, K.N. Robertson, T.S. Cameron, M. Gharghouri, Chem Commun. (2001) 1176-1177.

[27] J.G. Nery, Y.P. Mascarenhas, A.K. Cheetham, Microporous Mesoporous Mater. 57 (2003) 229-248.

[28] V.A. Drebushchak, Measurements of heat of zeolite dehydration by scanning heating, J. Therm. Anal. Calorim. 58 (1999) 653-662.

[29] M.E. Brown, Introduction to Thermal Analysis: Techniques and Applications, Chapman \& Hall, New York, 1988, pp. 174-202.

[30] T.A. Ostomel, Q. Shi, P.K. Stoimenov, G.D. Stucky, Langmuir ACS J. Surfaces Colloids 23 (2007) 11233-11238.

[31] M. Alkan, Ö. Demirbaş, M. Doğan, J. Colloid Interface Sci. 281 (2005) 240-248.

[32] M.L. Fisher, M. Colic, M.P. Rao, F.F. Lange, J. Am. Ceram. Soc. 84 (2001) 713-718.

[33] T. Frising, P. Leflaive, Micropor. Mesopor. Mat. 114 (2008) 27-63.

[34] V. Nikolakis, Curr. Opin. Colloid Interface Sci. 10 (2005) 203-210.

[35] J.H. Griffin, Proc. Natl. Acad. Sci. U. S. Am. 75 (1978) 1998-2002.

[36] T. Kuzniatsova, Y. Kim, K. Shqau, P.K. Dutta, H. Verweij, Microporous Mesoporous Mater. 103 (2007) 102-107.

[37] W.L. Yang, X.D. Wang, Y. Tang, Y.J. Wang, C. Ke, S.K. Fu, J. Macromol. Sci. Part 39 (2002) 509-526.
[38] D. Tarn, C.E. Ashley, M. Xue, E.C. Carnes, J.I. Zink, C.J. Brinker, Acc. Chem. Res. 46 (2013) 792-801.

[39] H.T. Peng, S.G. Rhind, Clin. Appl. Thromb.; Off. J. Int. Acad. Clin. Appl. Thromb. 21 (2015) 497-512.

[40] P.F. Glidden, C. Malaska, S.W. Herring, Clin. Appl. Thromb. Hemost. 6 (2000) 226-233.

[41] M. Thakur, A.B. Ahmed, IJPUT 1 (2012) 25-29.

[42] T.A. Ostomel, Q.H. Shi, G.D. Stucky, J. Am. Chem. Soc. 128 (2006) 8384-8385.

[43] M. Hoffman, Remodeling the blood coagulation cascade, J. Thromb. Thrombolysis 16 (2003) 17-20.

[44] J. Li, W. Cao, X.X. Lv, L. Jiang, Y.J. Li, W.Z. Li, S.Z. Chen, X.Y. Li, Acta Pharmacol. Sin. 34 (2013) 367-372.

[45] F. Arnaud, T. Tomori, W. Carr, A. McKeague, K. Teranishi, K. Prusaczyk, R. McCarron, Ann. Biomed. Eng. 36 (2008) 1708-1713.

[46] A.E. Pusateri, S.J. McCarthy, K.W. Gregory, R.A. Harris, L. Cardenas, A.T. McManus, C.W. Goodwin, J. Trauma 54 (2003) 177-182.

[47] V. Gramlich, W.M. Meier, The Crystal Structure of Hydrated NaA: a Detailed Refinement of a Pseudosymmetric Zeolite Structure, Database of Zeolite Structures. http://www.iza-structure.org/databases/.

[48] W.H. Baur, On the Cation and Water Positions in Faujasite Database of Zeolite Structures. http://www.iza-structure.org/databases/.

[49] T. Hahn, Space-Group Symmetry. International Tables for Crystallography, vol, A, Reidel, Dordrecht, 1983. 